\title{
Experimental Study on Flow Structure around Spur Dikes of Different Types
}

\author{
TaoYu $^{1,2^{*}}$, QiuqianDuan ${ }^{1,2}$, PingyiWang ${ }^{1,2^{*}}$, CaixiaMeng ${ }^{1,2}$, RanLu $^{1,2}$ \\ ${ }^{l}$ National Engineering Research Center for Inland Waterway Regulation, Chongqing Jiaotong \\ University, Chongqing, China \\ ${ }^{2}$ Key Laboratory of Hydraulic and Waterway Engineering of the Ministry of Education, Chongqing \\ Jiaotong University, Chongqing, China \\ *Corresponding Author.
}

\begin{abstract}
As water damage phenomenon of spur dike exists generally, spur dike must be maintained in order to ensure its regulation function, but its structure changed in the process of maintenance. In order to find out flow structure around the spur dike of different pattens, through generalized flume model tests, variation characteristics of water surface profile and flow velocity around the spur dike of five different pattens were analysed. The results show that the straight head had a greater influence than hook head spur dike on the water surface profile, circular cross-section had smaller effects than trapezoidal cross-section spur dike on the water surface profile; Velocity of Choke area and contraction order from large to small is trapezoidal cross-section and fan straight head dike, trapezoidal cross-section and arc straight head dike, arc section and arc straight head dam, trapezoidal cross-section and fan hook head dike, trapezoidal cross-section arc hook head dike; Cross section vertical velocity distribution from large to small is trapezoidal cross-section and fan hook head dam, trapezoidal cross-section and circular straight head dike, arc cross-section and circular straight head dam, trapezoidal cross-section and circular hook head dike.
\end{abstract}

Keywords: spur dike,flow structure, structural type, flume experiment

\section{Introduction}

Due to the strong three-dimensional characteristics of the flow around the spur dike, some details of the flow around the spur dike cannot be described accurately in theory or experiment in the early stage. Therefore, model test is often used to solve this problem. Windel first studied the influence of the flow field around the single impervious spur dike based on the flume test, then C.T. Altuinin carried out a lot of experimental research on this ${ }^{[1]}$. Ahmed ${ }^{[2]}$ carried out the first test on the flow around the spur dike, which successfully recorded the change of water surface height around the spur dike. After that, Fujiwara, Shiba, Tominaga, Shimizu and Muneta carried out the experimental study on the flow characteristics near the spur dike when it was submerged, and studied the turbulence characteristics around the spur dike ${ }^{[3]}$. Shoji Fukuoka ${ }^{[4]}$ developed a three-dimensional mathematical model to determine the optimal layout of spur dike in the bend, and the model is in good agreement with the model test results in terms of riverbed deformation and three-dimensional flow field. James mentioned that using adv (Acoustic Doppler Velocimeter) to study the three-dimensional flow field near the dam body will get good results ${ }^{[5]}$. Cheng et al. studied the effect of different hook angles and different hook length combinations on the time-varying field, and analyzed the internal mechanism of the effect ${ }^{[6]}$. Lv et al. studied the flow structure around the spur dike by using flow visualization and sheet light source technology ${ }^{[7]}$. It was found that horse-shoe vortex and Carmen vortex would form respectively in the upstream and the head of the spur dike. Zhou et al established a three-dimensional large eddy simulation mathematical model of water flow, and compared the flow movement characteristics near three kinds of groins (overhanging, positive overhanging, overhanging), which showed that the non submerged groins had a greater impact on the flow movement, and the overhanging groins had a better protection effect on the dam head[8]. Duo analyzed the flow structure around the overflow spur dike through a large number of hydraulic model tests, and determined the scour depth calculation formula of the overflow spur dike ${ }^{[9]}$. Guo et al. carried out experimental 
research on the flow characteristics under two working conditions of the existence and absence of spur dike in the bend, and summarized the characteristics of the water surface transverse gradient, transverse circulation, velocity redistribution and so on[10]. Zhou et al. conducted a systematic experimental study on the flow characteristics near the spur, and comprehensively analyzed the three-dimensional time average velocity and water surface morphology of the flow near the spur in the bend ${ }^{[11]}$. Wang Xiandeng et al. analyzed the flow pattern near the spur dike under the submerged and non submerged conditions, and then analyzed the mechanism of water damage of the spur dike ${ }^{[12]}$. Rong et al. established a mathematical model to describe the law of flow movement near the spur dike under the action of tidal bore ${ }^{[13]}$. The results show that the flow field and free water surface near the spur dike vary greatly at the initial tide. Yu et al. adopted flume test and three-dimensional shallow water model, the effect of dike head slope on the adjustment of flow structure near spur dike under submerged condition is studied ${ }^{[14]}$.

It can be seen that scholars have conducted in-depth research on the flow structure around the spur dike, and have a deep understanding of the changes and causes of the hydrodynamic field around the spur dike. However, there are still a large number of spur dikes destroyed by water in actual projects. Spur dikes often need to be maintained for many times to gradually become stable, which makes the structural type of spur dikes change greatly, which is manifested in the widening of dam head and serious abrasion of dam body, which makes the hydrodynamic field around the spur dikes inconsistent with the engineering design. How to change the flow structure before and after the spur dike type changes Therefore, in this paper, five different types of spur dike structures are studied. The research results have an important guiding role for engineering design and construction, and can provide reference for improving spur dike structure.

\section{Test plan and instruments}

The test was carried out in a rectangular glass flume with a length of $30 \mathrm{~m}$ and a width of $2 \mathrm{~m}$. The layout of the model test is shown in Figure 1. Due to the wide water surface of the natural river and the narrow test flume, the design of the model spur dike is mainly based on the local normal generalized design of the spur dike structure which is common in the upper reaches of the Yangtze River channel where the spur dike is seriously damaged by water. The scale of the model is $1: 40$. According to the requirements of technical code for waterway regulation engineering [15], the upstream slope is $1: 1.5$, the downstream slope is $1: 2$, and the riverward slope is $1: 2.5$. In order to compare the characteristics of flow structure changes around different types of spur dikes, five types of spur dikes are studied in the experiment, including the trapezoid section arc straight head (dike type 1), the trapezoid section arc hook head (dike type 2), the trapezoid section fan straight head (dike type 3), the trapezoid section fan hook head (dike type 4), and the arc section straight head (dike type 5). See Figure 2 for the five design models of spur dike in sequence. In this paper, the length of spur dike is the length of spur dike body, excluding the length of spur dike head. The spur dike is arranged on the left bank of the flume. The spur dike body is cement mortar masonry dam body. The dam body is vertical to the side wall of the flume. The section form of the dam body is shown in Figure 3. The dam height is $10 \mathrm{~cm}$ and the dam length is $50 \mathrm{~cm}$. The slope of different positions of the dam head (dotted line in Figure 2) is smoothly connected according to the slope of the upstream slope, the upstream slope and the downstream slope. 


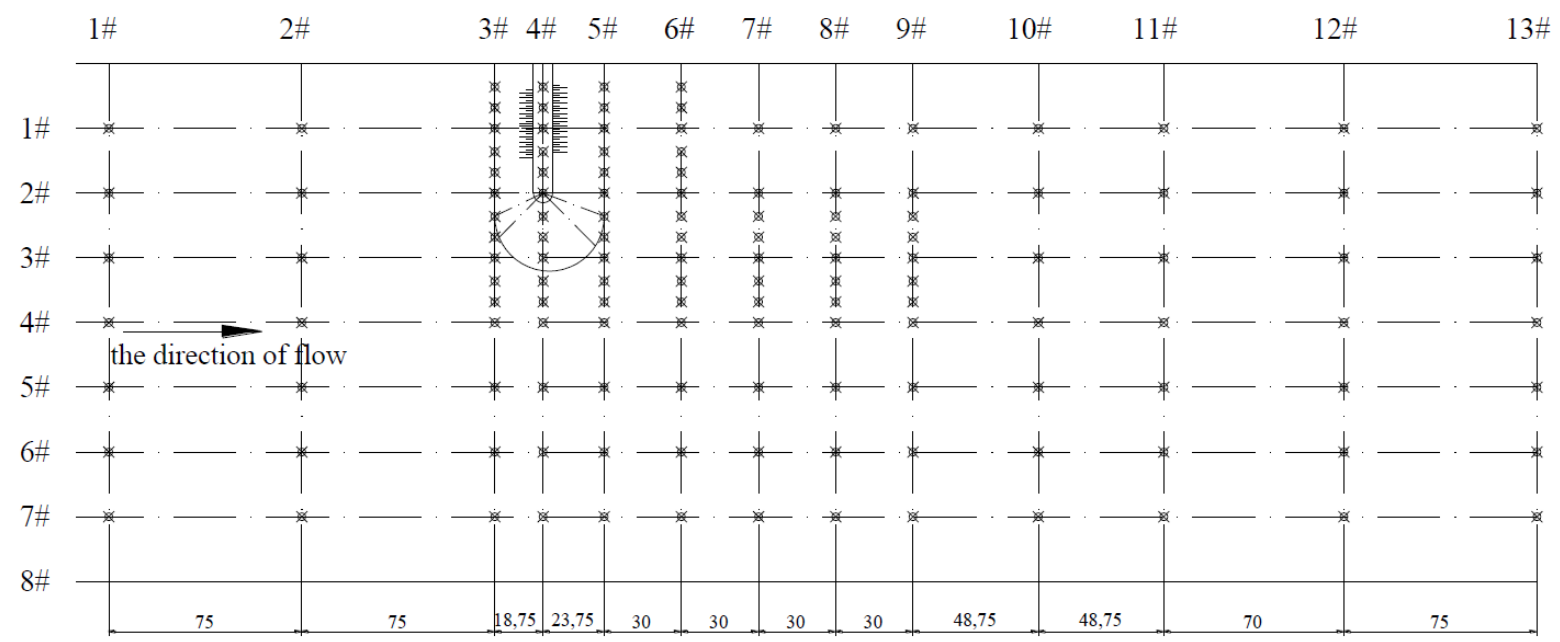

Fig 1: Layout of experimental model (marked unit in the figure: $\mathrm{cm}$, the same below)
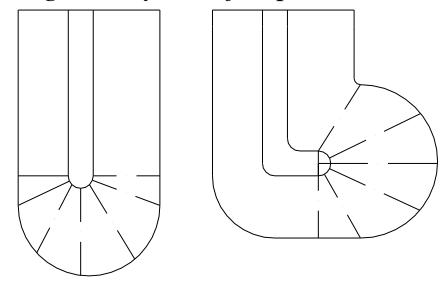

(a) dike type 1 b) dike type 2

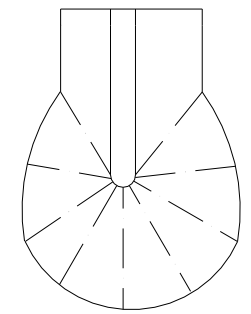

(c) dike type 3
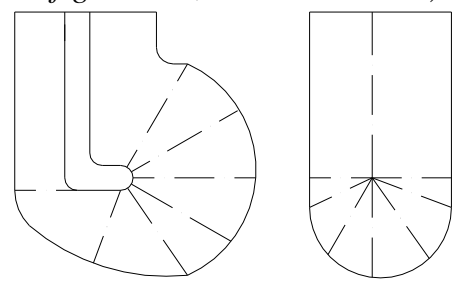

d) dike type 4

(e) dike type 5

Fig 2: Planar layout diagram of five types of spur dikes

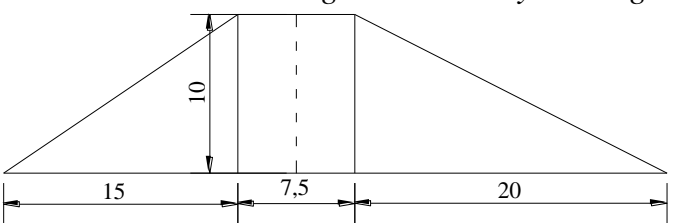

(a) Trapezoidal cross section

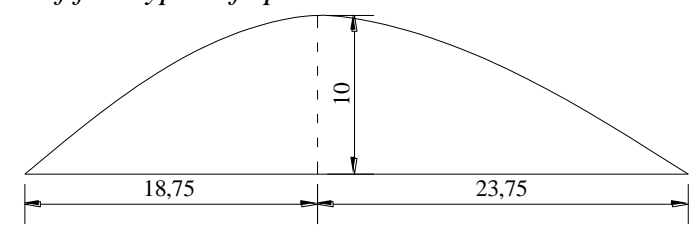

(b) Circular arc cross section

Fig 3: Dike body cross section diagram

The inlet flow is controlled by automatic flow control system. The water level in front of the dam is controlled by the water level measuring needle, the real-time water level is measured by the ultrasonic automatic water level measuring system, and the velocity is measured by three-dimensional velocity measuring system. The sampling frequency is $30 \mathrm{~Hz}$. The sampling time of each point is $30 \mathrm{~s}$. In the test, the control inlet flow rate is $95 \mathrm{l} / \mathrm{s}$ and the water depth in front of the dam is $14 \mathrm{~cm}$.

\section{Distribution of water surface around spur dikes of different types}

3.1 Variation of longitudinal water surface with different dike types

Taking the scheme with a flow of $95 \mathrm{l} / \mathrm{s}$, a water depth of $4 \mathrm{~cm}$ in the middle of Ding Dam crest and a dam length of $50 \mathrm{~cm}$ as an example, the water surface lines of $2 \#, 6 \#$ and $8 \#$ longitudinal sections under five different structural types are shown in Fig. 4. 

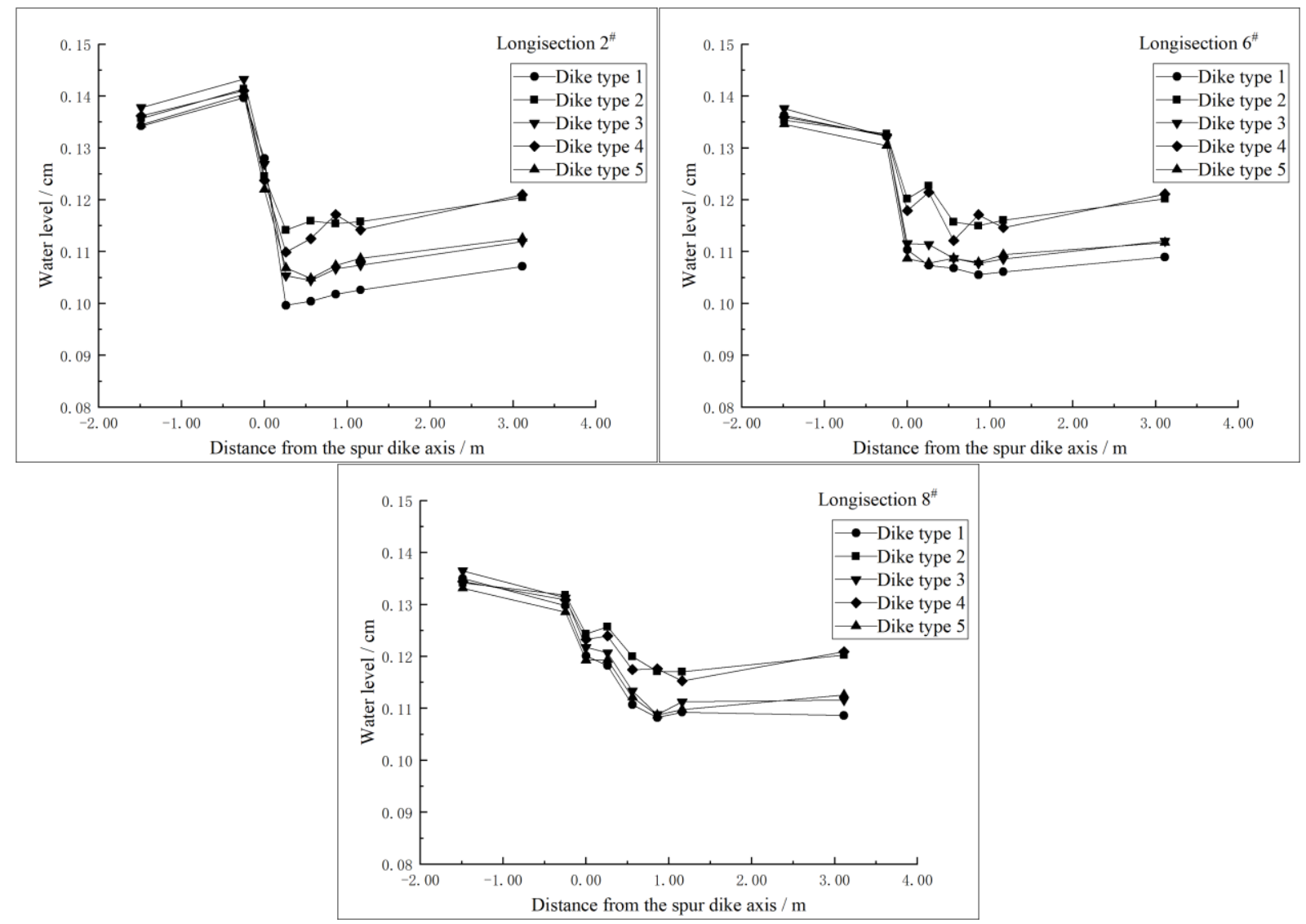

Fig 4: Variation of longitudinal water surface with different dike types

From the change trend of the water surface line of different vertical sections, it can be found that the same pattern under the five dam types is that the No. 2 vertical section (the vertical section where the dam body is located) has a large water drop, the No. 6 vertical section (the mainstream area) and the No. 8 vertical section. (Close to the right bank and away from the spur dike) The water fall is small; At No. 2 longitudinal section, the dam type with the largest water drop on the upstream and downstream of the spur dam is a trapezoidal section arc straight dam, and the dam type with the smallest water drop is a trapezoidal section arc hook dam, and the hook head spur dam has a lower water drop than a straight spur dam. Small, this is mainly because the water blocking area of the hook head spur dam is small, which makes the backwater in front of the dam low; At No. 6 longitudinal section, the water level in front of the Straight head spur dam began to fall. After the water flow crossed the axis of the dam, the water level fell less. When it reached about $50 \mathrm{~cm}$ downstream of the dam, the water level began to rise slowly. Secondary backwater, but the water level of the arc hook head spur dike in the falling section behind the dam is slightly higher than the fan hook head spur dam. The highest and lowest water level downstream of the dam axis is the trapezoidal section arc hook head and the trapezoidal cross section arc straight spur dike, but the hook head the spur dike falls less than the straight spur dike; Secondary backwaters occurred in various dam types at No. 8 longitudinal section. The highest and lowest water levels downstream of the dam axis were still trapezoidal section arc hook head and trapezoidal section arc straight spur dam. The hook head spur dam fell less than the straight end. For the spur dike, the water level of the straight spur dike with circular arc section is generally in the middle of the other four types of dams.

\subsection{Variation of transverse water surface with different dike types}

With a flow of $95 \mathrm{l} / \mathrm{s}$, a water depth of $4 \mathrm{~cm}$ in the middle of the spur dam crest and a dam length of $l=50 \mathrm{~cm}$ as an example, the water surface lines of 2\#, 3\#, 4\# and 6\# cross-sections under five different structural types are shown in Fig. 5. 

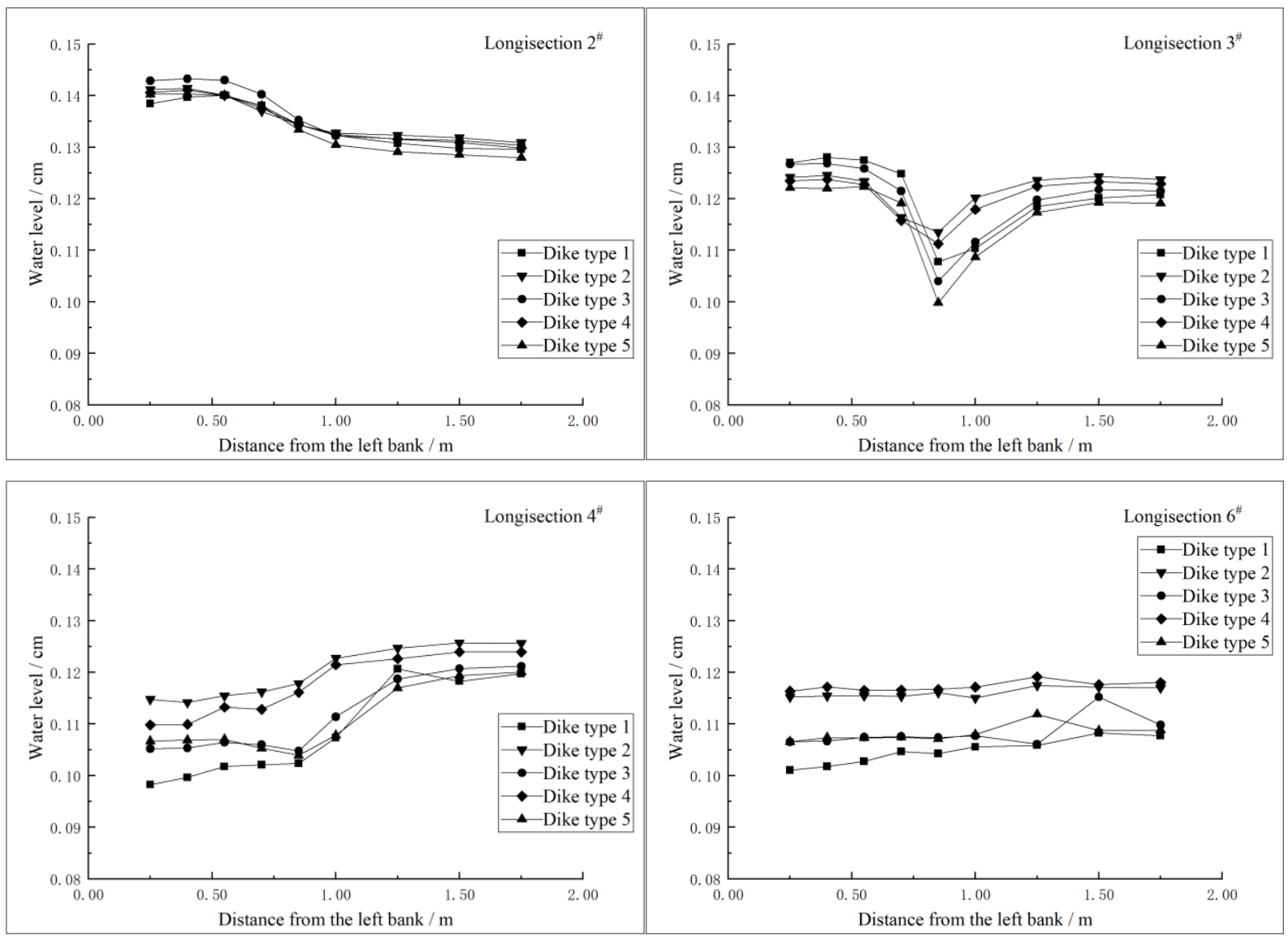

Fig 5: Variation of transverse water surface with different dike types

It can be seen from Fig. 5 that the variation trend of water surface lines in each cross-section of five different structure types is basically the same, the water level of the fan-shaped straight head pike in the backwater area of the upstream 2\# cross-section is the highest, and the water level of the circular straight head pike in the circular section is the lowest in the main stream area. 2\# The cross section (the dam axis section) has a large change in the transverse drop, and the change of the hook head spur dike is smaller than that of the straight head spur dike; The overall water level of the circular-arc straight-head spur dike at Facing the water slope (3\#) section is better than the bottom of the trapezoidal-section circular-arc straight-head spur dike. It is higher than the trapezoidal cross-section and the arc straight spur dike, but the water level difference between the two on the opposite bank of the spur dike is smaller; The water level changes slightly behind the dam. The water level of the fan hook head of the trapezoidal section is the highest, and the water level of the straight spur dam is lower than the hook head spur dam. This trend of change is mainly due to the large water blocking degree of the straight spur and the strong water jetting effect, which makes the water level in the blocking area relatively high, while the water level in the downstream area is relatively low, so the water flow falls in the narrow section. The water is larger. The fan-shaped head of the straight spur dike has the largest water blocking degree; The arc-section spur dam has less resistance to the water flow, and the overflow on the side of the spur dam is relatively large, making the water level in the downstream area on the opposite bank of the spur relatively low.

Arc section straight head and the trapezoidal cross-section straight spur dike in 6 \# cross-sectional spur dike on the other side horizontal gradient change is bigger, mainly because the area is located in the mainstream area and mixed area of re-circulation region and the vortex made currents to spur dike on the other side (right), and from the spur dike flow of the movement to the left on the other side, heading up.

\section{IV.Flow velocity distribution around spur dikes of different types}


4.1 Flow velocity distribution of cross sections of different dike types

Taking the scheme with a flow rate of $95 \mathrm{l} / \mathrm{s}$, a water depth of $4 \mathrm{~cm}$ in the middle of Ding Dam crest and a dam length of $50 \mathrm{~cm}$ as an example, the average vertical velocity (the same below) of cross-sections $3 \#, 4 \#$, 5\# and 7\# under five different structural types is shown in Fig. 6.

The flow rate of the five dam structure types is basically the same from the left bank to the middle section and then to the right bank. The left bank is the backflow area behind the dam. The flow pattern in the backflow area is turbulent due to the jet flow and the Karman vortex. The forward flow rate is not large and often It is difficult to accurately measure the three-dimensional flow velocity due to the occurrence of backflow, lateral flow, vortex flow, and exchange of top water flow with bottom water flow. The water drop is the largest at the head of the dam, and the velocity of each dam type rises rapidly until it approaches the right bank and tends to be uniform and stable. The streamline on the right bank is straight and stable, and the dam-shaped curves are relatively stable with little change. From sections $3 \#$ and $4 \#$, the flow velocity of the fan-shaped straight head dam is larger in the blocking zone and the contraction section, followed by the circular arc straight head dam, the circular arc straight head dam, the fan-shaped straight head dam and the circular arc straight head dam. This is because from the dam body retaining water, the fan-shaped straight head dam has strong water resistance, followed by trapezoidal circular straight head dam, circular straight head dam with circular arc section, trapezoidal fan-shaped hooked head dam and trapezoidal circular hooked head dam. The backwater produced in front of the trapezoidal section of the flip-head dam is also larger, resulting in greater water drop at the dam head, while the sections $3 \#$, and $4 \#$ are just at the position where the backwater area starts to fall, so the flow velocity is higher. The contraction section therefore has a higher flow rate.

Judging from the sections $5 \#$ and $7 \#$, the backflow area behind the left bank dam is affected by factors such as jet flow, turbulence and eddy currents, and bottoming of the dam, and the flow pattern is turbulent, and there is no obvious rule to follow. \#, 4\# have the same rule of cross-section. Among them, the water retaining capacity of the trapezoidal section arc straight dam is basically the same as that of the arc section arc straight dam, but the dam body contour curve of the arc section arc straight dam is smoother, so it is slightly smaller than the trapezoidal section arc straight dam.
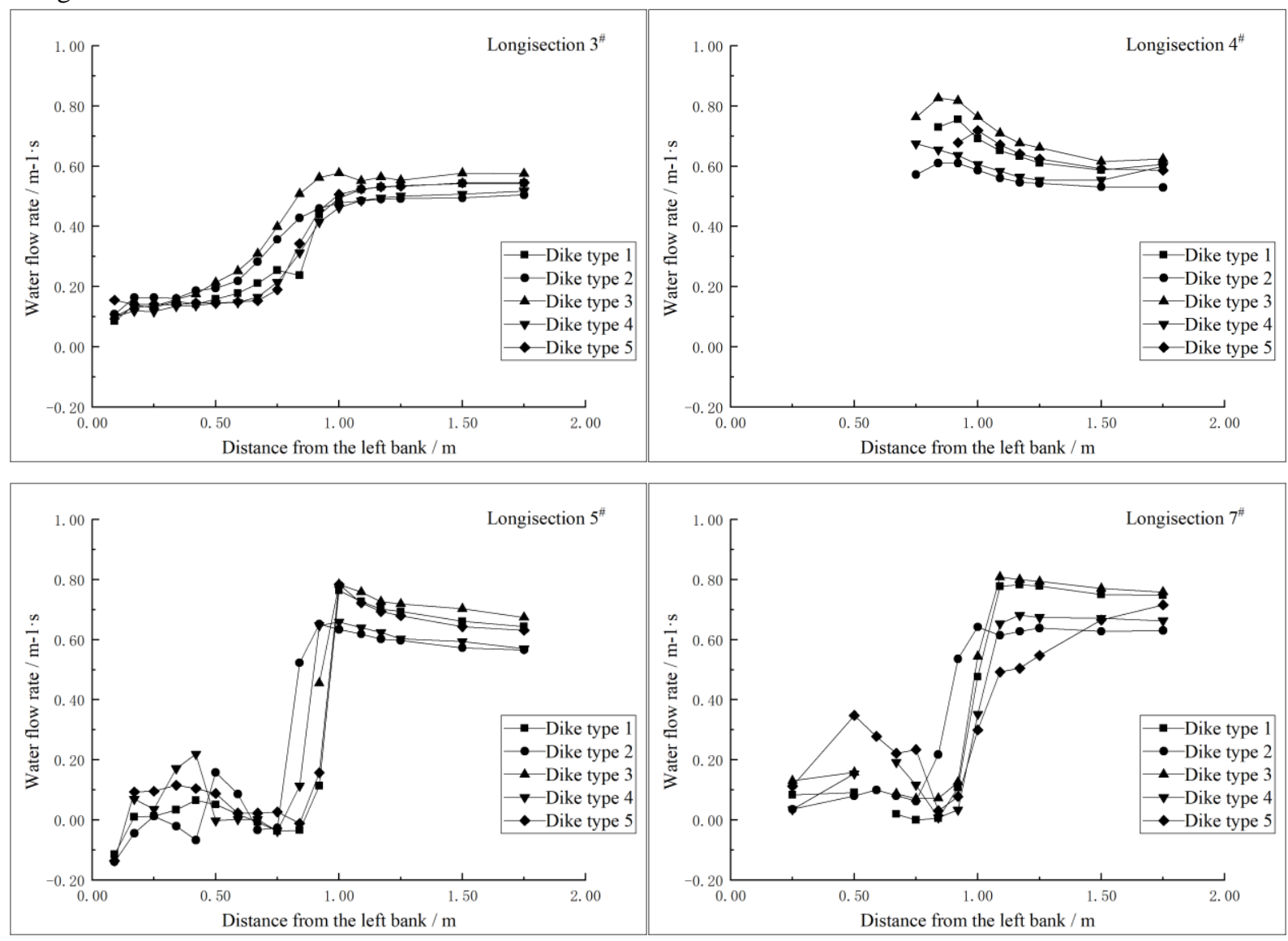

ISSN: 0010-8189

(C) CONVERTER 2020

www.converter-magazine.info 
Fig 6: Comparison of cross sectional water flow rate with different dike types

4.2 Vertical velocity distribution of cross sections of different dike types

Spur dike around the bed surface is the vertical component of the water and sediment movement and one of the important causes of waterlogging dam, therefore, selected spur dike near the $3 \#, 4 \#, 5$ \#, analysis of $\mathrm{Q}=95 \mathrm{l} / \mathrm{s}, \mathrm{L}=$ $50 \mathrm{~cm}$ under the condition of four kinds of working condition, the trapezoidal cross-section arc straight head, trapezoidal cross-section hook, trapezoidal cross-section fan hook and arc section head straight spur dike, Make the contour map of the vertical velocity of each section and analyze the distribution of the vertical velocity of the water near the spur dike.

Dike type 1

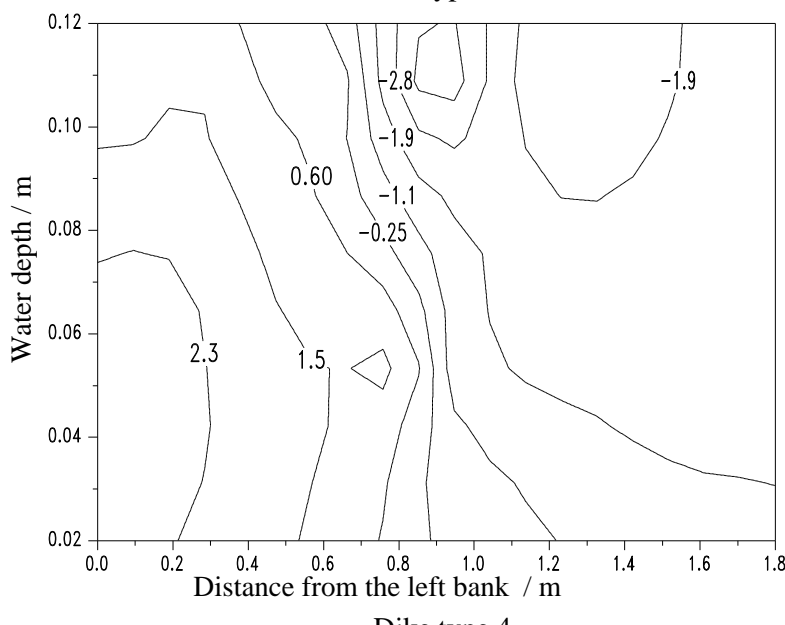

Dike type 4

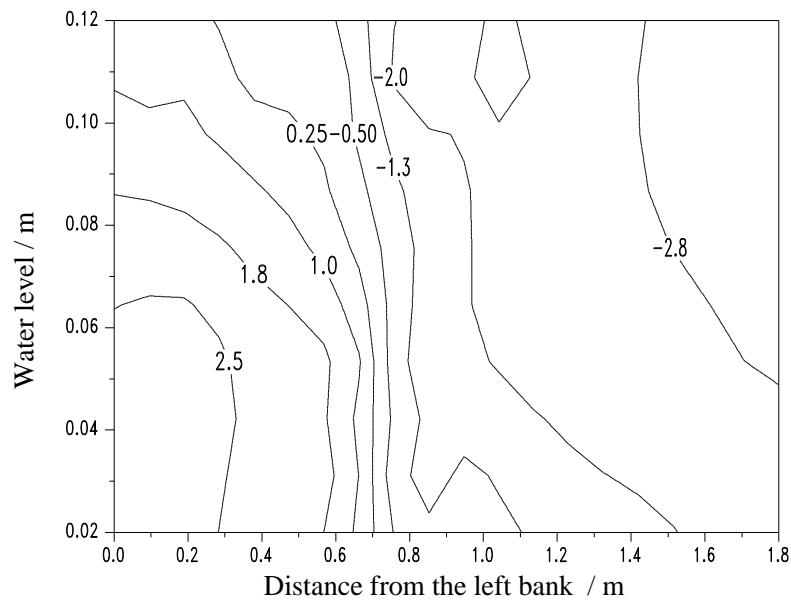

Dike type 2

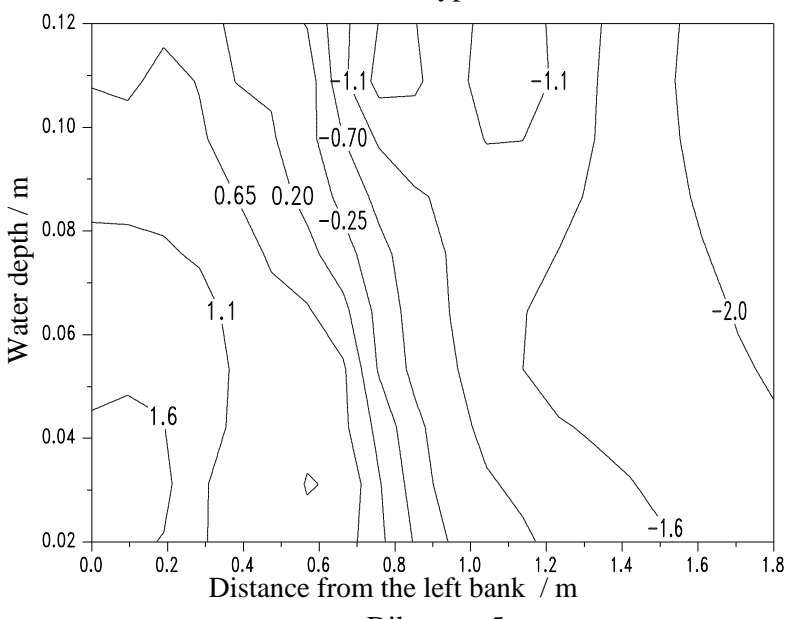

Dike type 5

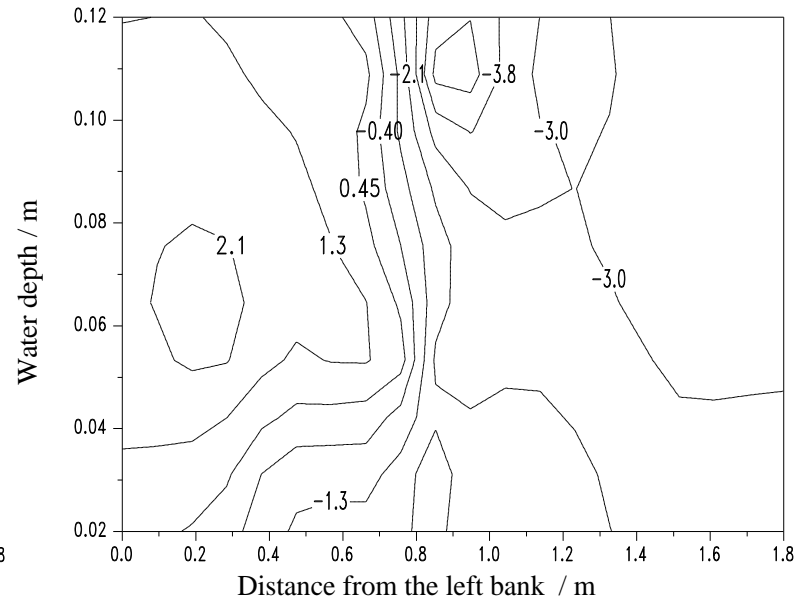

Fig 7: Vertical velocity contour map of No.3 section of different dike types (the unit of the contour in the figure is $\mathrm{m} / \mathrm{s}$, the same below)

It can be seen from Figure 7 that due to the water facing slope of section 3\#, the left bank is the backwater area in front of the dam. Part of the water flows across the top of the dam and continues downward, and part of the water flows rightward along the dam body and bypasses the spur dam. The coordinate system of the measuring instrument is that the $\mathrm{Z}$ axis is positive, so the flow velocity in the area of $0 \mathrm{~m} \sim 0.6 \mathrm{~m}$ on the left bank is basically positive, which means that the water flows upward here. After the water flow touches the spur dike, because the spur dike has a slope, the underflow quickly turns upward after being blocked, and the velocity gradually decreases as the water rises. Therefore, the velocity on the left bank shows a distribution law of underflow velocity greater than surface velocity in the vertical direction. In the spur dam head position and the contraction section on the right bank, the dam head falls and the water surface drops in the entire dam head area and the contraction section. The vertical negative velocity of the surface flow is relatively large. Because the bottom of the flume is a closed boundary, the descending 
water flow touches the bottom of the flume. Energy loss and downward velocity decrease, so in the dam head area and the contraction section on the right bank, the velocity in the vertical direction shows a distribution law of surface flow velocity greater than underflow velocity. On the left bank, it can be seen that the vertical velocity distribution law between the four working conditions is that the vertical positive velocity of the fan-shaped hook of the trapezoidal section is larger, followed by the trapezoidal section with the arc-shaped straight end, and the arc section is round again The arc-shaped straight head, and finally the trapezoidal cross-section arc-shaped hook head. The degree of stagnation is the same as the four working conditions. It can be seen that due to the difference in water retention, the vertical flow velocity is different, and finally the degree of stagnation is different. The greater the water drop, the greater the vertical velocity of the falling water flow. The vertical velocity distribution of the spur dike head and the contraction section on the right bank is the same.

Dike type 1

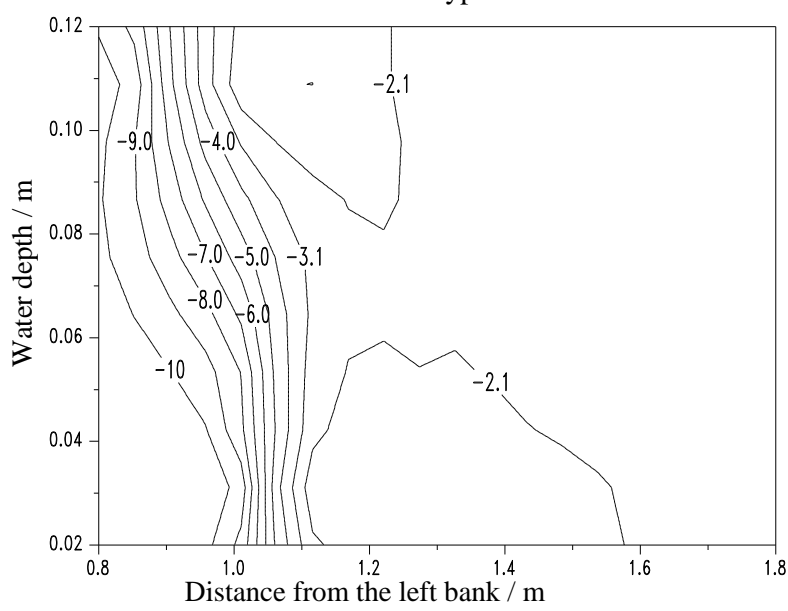

Dike type 4

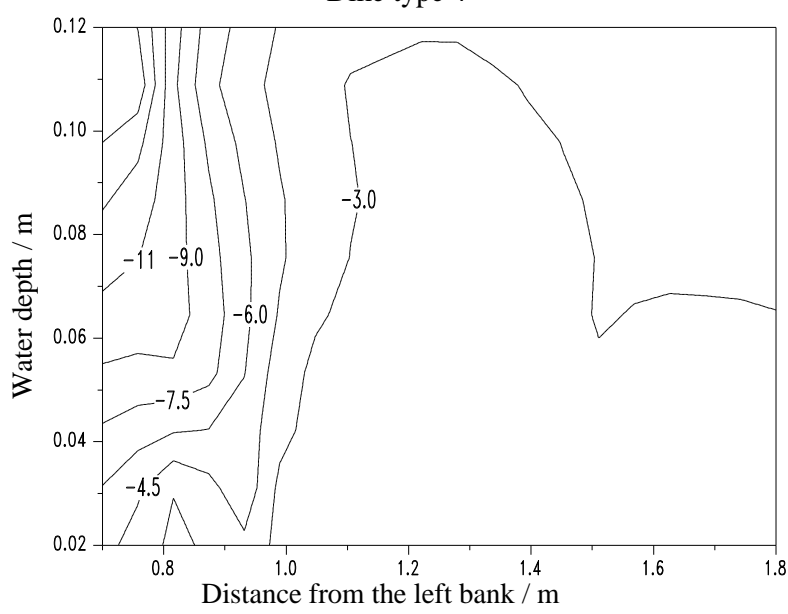

Dike type 2

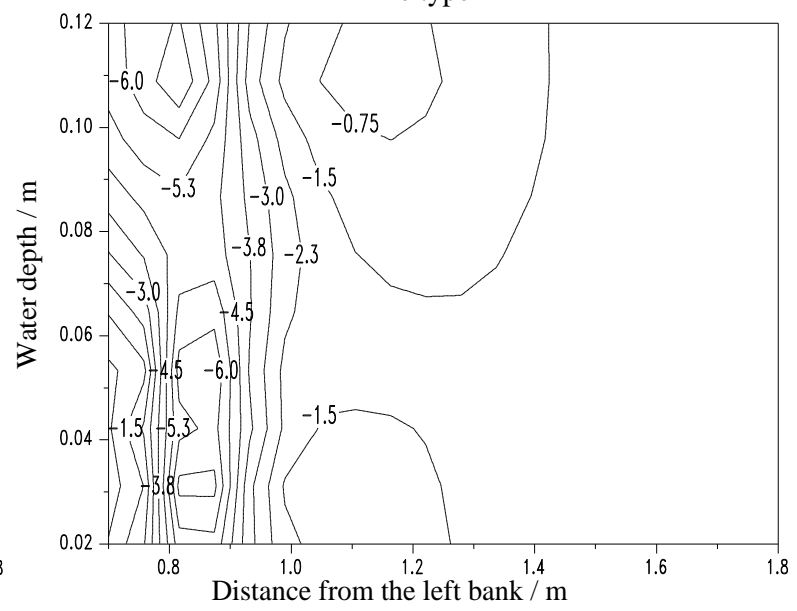

Dike type 5

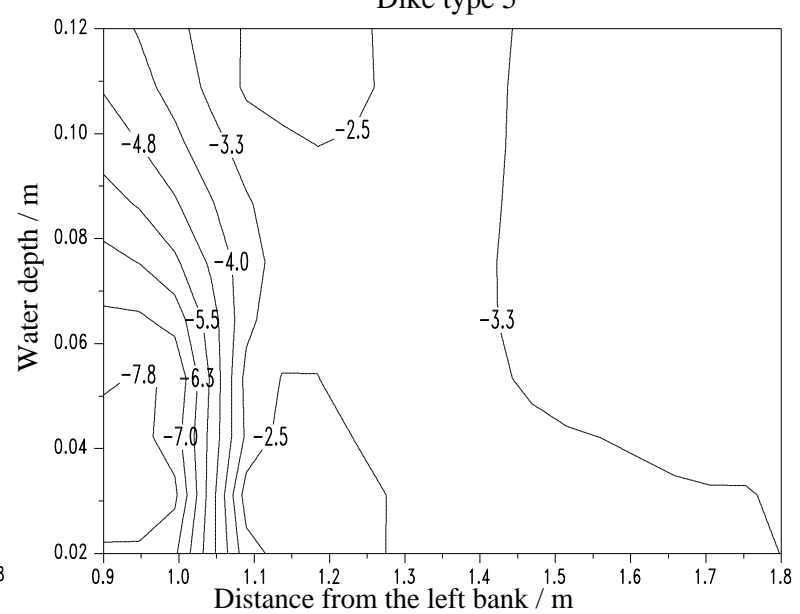

Fig 8: Vertical velocity contour map of No.4 section of different dike types

As can be seen from Fig.8, Section 4\# is located at the dam axis, and the flow velocity in the dam crest area cannot be measured, so the abscissa of the contour map ranges from $0.8 \mathrm{~m}$ to $1.8 \mathrm{~m}$. Because the dam head drops, the water surface drops, the bottom of the tank is closed boundary, so the vertical flow velocity in the vertical direction shows the distribution law of surface flow velocity is greater than bottom flow velocity. Similarly, the vertical velocity distribution in the lateral direction shows a law of distribution that the closer to the dam head, the greater the vertical velocity. The reason is that the dam head is the location where the water falls the most, where the water surface gradient drops the most, and the flow potential energy is converted into kinetic energy the most.

Because the size of the water drop is that the trapezoidal section has a larger fan-shaped hook, followed by a trapezoidal section and an arc-shaped straight head, then an arc-shaped straight head with a circular arc section, and 
finally a trapezoidal cross-section arc-shaped hook. The greater the water drop, the greater the vertical velocity of the downflow, the direct result of the vertical velocity distribution of the spur dike head and the contraction section on the right bank is also the same.
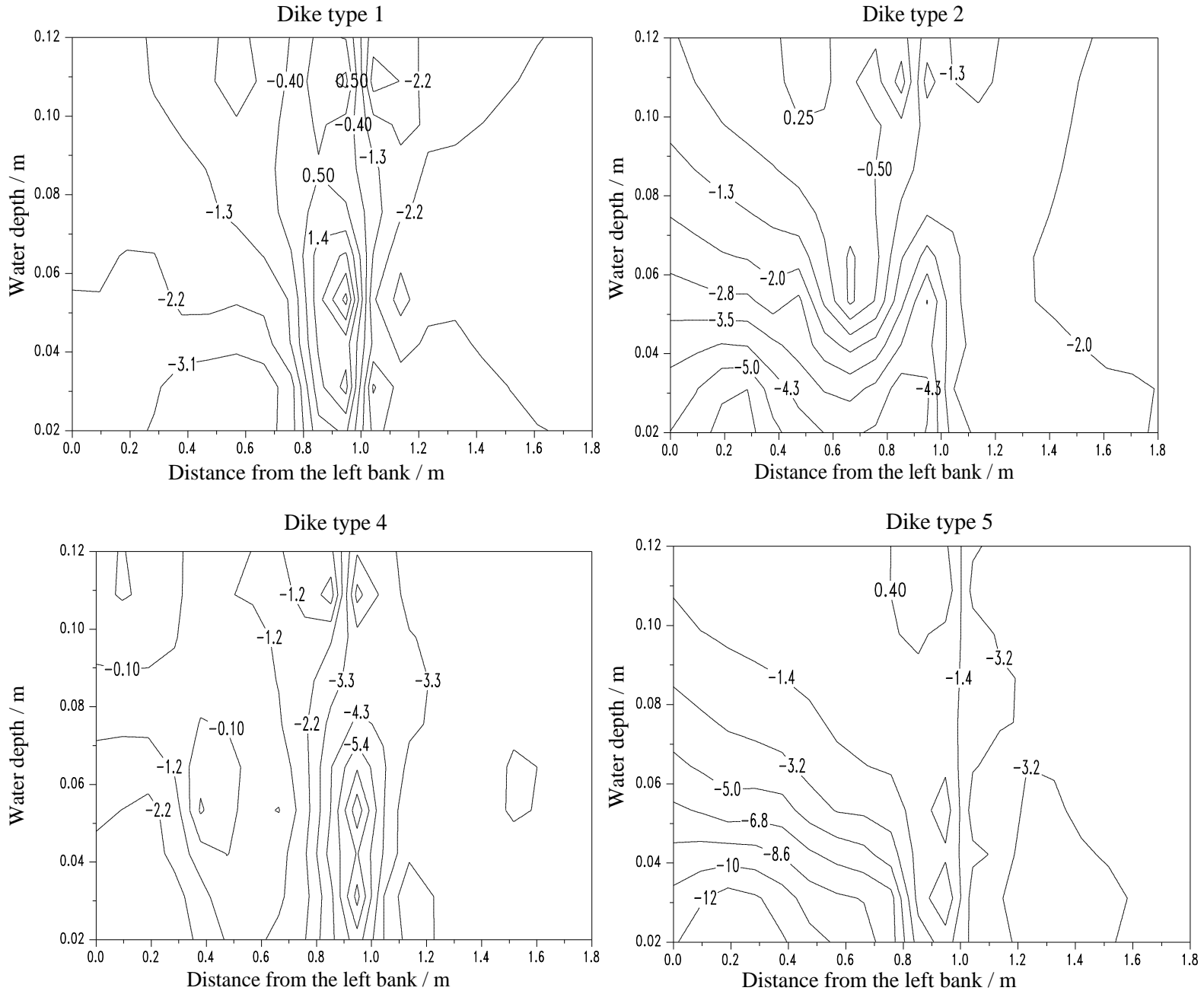

Fig 9: Vertical velocity contour map of No.5 section of different dike types

It can be seen from the figure 9, section 5\# of the dam along the back water slope, on the left bank is located in the dam after reflow area, water flow over the top, after a sharp decline on the back slope water, formation dip water flow, water dip after contact with the bottom of the sink, part of the water turn back up, so the flow in the bottom of a vertical direction in the left bank of the vertical velocity is more negative to the flow of water, and the velocity is larger, the forward velocity of surface flow.Among them, there is a large forward flow velocity in the bottom part of the trapezoidal section of the circular hook head dam, which is caused by the water flowing back quickly after hitting the bottom of the flume after reaching the bottom. The back of the dam head and the right bank behind the dam are still in the area of falling water, and the water level continues to drop, so the distribution rule is in the vertical direction, and the negative velocity of surface flow is greater than that of bottom flow.

After the jetty head and the right bank area, because the drop degree of the trapezoidal cross-section fan hook is bigger, followed by trapezoidal cross-section straight head of circular arc form, again for circular section of straight head of circular arc form, finally for the trapezoidal section circular hook, the larger the drop, the greater the vertical speed drop water, so the led directly to the head of spur dike and vertical velocity distribution law for the right bank contraction with the agreement.

\section{Conclusion}

ISSN: 0010-8189

(C) CONVERTER 2020

www.converter-magazine.info 
(1) When the structure forms of the dam are different, on the left bank of the dam near the spur dike and near the dam head, the influence of the spur dike on the longitudinal water surface line of the spur dike is greater, while the spur dike on the vertical water surface line of the spur dike is smaller. The change of water level around the spur dike with the arc section is relatively small.

(2) The water level in the blocking area in front of the trapezoidal section of the fan-shaped straight head dam is the highest, and the water level in the downstream area of the circular straight head dam is the lowest in the circular straight head dam. There are large transverse drop changes in the narrow section of beam, but the change of straight head dam is greater than that of hook head dam. The water level of fan-shaped hook dam with trapezoidal section is the highest behind the dam, and the water level of hook dam is higher than that of straight head dam.

(3) the degree of dam water retaining velocity for different cause choke area and contraction order from large to small is trapezoidal cross-section fan straight head dam, trapezoidal cross-section arc straight head dam, arc section straight head dam, trapezoidal cross-section fan hook and trapezoidal cross-section arc hook, the trapezoidal cross-section arc straight head dam and arc section straight head dam block water basic same, But the contour curve of circular arc straight head dam with circular arc section is more smooth, so it is slightly smaller than that of trapezoidal section circular arc straight head dam.

(4) The bottom flow velocity in the vertical direction of the left bank of the frontal slope section is greater than the surface flow velocity, and the surface flow velocity is greater than the bottom flow velocity at the head of the spur dam and at the contraction section of the right bank; The vertical velocity of surface flow in the main flow area of the dam axis section is greater than that of the bottom flow, and the closer to the dam head, the greater the vertical velocity is. The vertical velocity of the vertical direction behind the dam shows that the bottom flow is mostly negative flow, and the velocity is large, while the surface flow is mostly positive flow. The forward vertical velocity distribution of headwater slope, dam axis and backwater slope cross-section is in descending order: trapezoidal section fan hook, trapezoidal section circular arc straight head, circular arc straight head of circular arc section, trapezoidal section circular arc straight head.

\section{Acknowledgements}

This research was supported by National Key Research and Development Program of China (Grant No. 2016YFC0402106 ) , Chongqing Frontier and Applied Basic Research Program of China (Grant No. cstc2015jcyjA30004) and Chongqing Municipal Education Commission Science and Technology Research Program of China (Grant No. KJQN201800737). Thanks also go to the reviewers who provided valuable advices for the improvement of the manuscript.

\section{References}

[1] Y.F. Han, Study on bed formation of spur dike. Nanjing: Nanjing Institute of Hydraulic Research, 2003.

[2] M. Ahmed, Experiments on Design and Behavior of Spur dikes, Proc. Minnesota International Hydraulics Convention, Minneapolis, MN, p145-149.

[3] M. Ahmad, Experiments on design and behavior of spur dikes. Proc. Int. Hyd. Convention, New York, NY, USA: ASCE; 1953. pp. 145-159.

[4] N. Muneta, Y. Shimizu, Numerical Analysis Model with Spur-dikes Considering the Vertical Flow Ve3locity Distribution Annual Journal of Hydraulic Engineering, JSCE, No. 497, p31-39.

[5] Shoji. Fukuoko, (Japan). Arrangement of spur dams in curved river channels. Estuary and Coastal Engineering. 1995.5 (2): 72-79.

[6] James Fox. An Environmentally Friendly Barb Design for Washington State.Research \&Extension Regional Water Quality Conference.2002.

[7] C.H. Cheng, J. X. Liu, G. X. Xu, Experimental study on the influence of Gotou spur dam on flow structure. ISSN: 0010-8189 
Journal of Chongqing Jiaotong University. 1994(01): 58-69.

[8] Z.Y. Lv, B.S. Zhang, L.G. Hu, Research on three spur dikes. Fluid Mechanics Experiment and Measurement. 2002(02), 21-24.

[9] Y.L. Zhou, S.Z. Dao,Z.H. Gu, Study on the three-dimensional water movement characteristics near a non-submerged spur dike. Journal of Hydraulic Engineering. 2004(08), 46-53.

[10] W.Y. Duo, The flow structure around the flood spur dike and the calculation of its scour depth. Shanxi Transportation Science and Technology. 2005(6), 50-51.

[11] W.D. Guo, Y. Zhou, Y.Q. Zhang, etc.Analysis of the influence of spur dike on water flow in bends.Journal of Shenyang Agricultural University. 2006(04): 666-668.

[12] Y. Zhou, W.D. Guo, Y. Liang, et al. Flow pattern near non-submerged spur dike. China Rural Water and Hydropower. 2006(07): 82-84.

[13] X.D. Wang,D.X.Peng, W.Xia, Analysis of local flow structure and water damage mechanism of spur dam body. China Water Transport (second half of the month). 2009, 9(9): 189-190, 213.

[14] G.W. Rong, W.L. Wei , Y.L. Liu, et al. Numerical simulation study on the movement characteristics of water near a spur dam under tidal bore. Journal of Hydraulic Engineering. 2012(03): 296-301.

[15] S.B. Yu, Z.C. Chen, Y.F. Han, The effect of submerged spur dike slope on the adjustment of nearby water flow structure. Hydrodynamic Research and Progress Series A. 2012(01): 39-46.

[16] Ministry of Communications.JTJ312-2003.Technical Specifications for Waterway Regulation Engineering. Beijing: People's Communications Press, 2003: 61. 